NBER WORKING PAPER SERIES

\title{
THE ROLES OF COGNITIVE AND NON-COGNITIVE SKILLS IN MODERATING THE EFFECTS OF MIXED-ABILITY SCHOOLS ON LONG-TERM HEALTH
}

\author{
Anirban Basu \\ Andrew M. Jones \\ Pedro Rosa Dias \\ Working Paper 20811 \\ http://www.nber.org/papers/w20811 \\ NATIONAL BUREAU OF ECONOMIC RESEARCH \\ 1050 Massachusetts Avenue \\ Cambridge, MA 02138 \\ December 2014
}

Jones and Rosa Dias acknowledge funding from the Economic and Social Research Council under grant reference RES-060-0045. Basu acknowledges support from NIH research grants RC4CA155809 and R01CA155329. We are grateful for comments on earlier versions of this work from seminar participants at the University of Bergen, University of Chicago, University of Gothenburg, University of Lugano, University of Venice Ca' Foscari, University of Vienna and the 9th World Congress of the International Health Economics Association in Dublin. Opinions expressed are the authors' alone and do not reflect those of the University of Washington, NBER, University of York, University of Bergen and Monash University. The views expressed herein are those of the authors and do not necessarily reflect the views of the National Bureau of Economic Research.

NBER working papers are circulated for discussion and comment purposes. They have not been peerreviewed or been subject to the review by the NBER Board of Directors that accompanies official NBER publications.

(C) 2014 by Anirban Basu, Andrew M. Jones, and Pedro Rosa Dias. All rights reserved. Short sections of text, not to exceed two paragraphs, may be quoted without explicit permission provided that full credit, including $(\subset$ notice, is given to the source. 
The Roles of Cognitive and Non-Cognitive Skills in Moderating the Effects of Mixed-Ability Schools on Long-Term Health

Anirban Basu, Andrew M. Jones, and Pedro Rosa Dias

NBER Working Paper No. 20811

December 2014

JEL No. C21,C26,I12,I28

\begin{abstract}
We examine heterogeneity in the impacts of exposure to mixed-ability 'comprehensive' schools in adolescence on long-term health and smoking behaviour. We explore the roles that cognitive and non-cognitive skills may play in moderating these impacts. We use data from the 1958 National Child Development Study (NCDS) cohort, whose secondary schooling years lay within the transition years of a major reform that transformed secondary education in England and Wales from a selective system of schooling to mixed-ability comprehensive schools. We adopt a local instrumental variables approach to estimate person-centred treatment (PeT) effects of comprehensive over selective schooling system. Our results indicate that the newer comprehensive schooling system produced significant negative effects on long-term health and increased smoking behavior among a small fraction of individuals, for whom the effects were persistent over time. The ATE and TT were quantitatively similar and statistically insignificant indicating that cognitive abilities, the major driver for selection in to comprehensive schools, did not moderate the effects. The PeT effects indicate that individuals with lower non-cognitive skills were most likely to be negatively affected by exposure to mixed-ability schools. Our results also show that cigarette smoking could be a leading transmission channel of the long-term impact on health outcomes.
\end{abstract}

Anirban Basu

Departments of Health Services, Pharmacy and Economics

University of Washington

1959 NE Pacific St

Box - 357660

Seattle WA 98195

and NBER

basua@uw.edu

Andrew M. Jones

Department of Economics

University of York, University of Bergen and Monas

Heslington, York,

YO10 5DD, UK

andrew.jones@york.ac.uk
Pedro Rosa Dias

Department of Economics

University of Sussex

Sussex House, Falmer

Brighton, BN1 9RH, UK

P.Rosa-Dias@sussex.ac.uk 


\section{INTRODUCTION}

The recent literature on human capability formation (Cunha and Heckman, 2007, 2008, 2010; Conti et al., 2010, 2011 and Heckman et al. 2014) has amassed compelling evidence indicating that health behaviors and outcomes, as well as educational choices, are simultaneously determined from a very early age by a complex network of factors that include cognitive skills, socio-emotional development and initial health endowments. Although the positive association between education and health has long been established, it is vital for the guidance of economic policy to disentangle the causal impact of education on health from the effect of selection into distinct educational paths.

The applied literature has examined the health returns of two distinct dimensions of education: the length of schooling, and the type and quality of that schooling. Concerning the health returns to length of schooling, different identification strategies have allowed researchers to establish the existence of positive long-term mean effects of the attendance of further schooling, in particular years of extended compulsory education, on longevity and a wide range of health-related behaviors and outcomes: see, for example Currie and Moretti (2003), Lleras-Muney (2005), Kenkel et al. (2006), Oreopoulous (2006), Grimard and Parent (2007), Silles (2009), and Van Kippersluis et al. (2011). More recently, this body of evidence has been extended in several important directions.

Conti et al. $(2010,2011)$ use data from a large British cohort study to estimate factor models with unobserved components to go beyond mean effects and recover the full distribution of treatment effects for attendance at post-compulsory education. Their results show that the average marginal effect of post-compulsory education is typically higher than its estimated average treatment effect. The results indicate that the estimated 
mean effects hide considerable heterogeneity in responses: for example, the effectiveness of post-compulsory schooling in improving long-term health outcomes is highest for males with low levels of social development and high levels of cognitive ability.

Heckman et al. (2014) extend this evidence further. They use data from the 1979 National Longitudinal Survey of Youth to estimate a sequential discrete choice model with multiple schooling choices, covering the full range of participation decisions regarding schooling levels from high school attendance to the completion of a higher education degree. This model is identified using a set of instrumental variables, thereby allowing the estimation of policy-relevant treatment effects at different margins of the length of schooling. As in Conti et al. $(2010,2011)$, their results do not indicate that there was selection on gains but that education has beneficial effects on health and cigarette smoking, although the size of this effect varies considerably between different levels of schooling. Finally, within each level of schooling, the effect of education depends on individual characteristics, in particular on levels of ability. On average, high ability individuals benefit more, in terms of their physical health, from the completion of college degree than low ability ones. Interestingly, the converse happens in the case of the effect of college completion on important dimensions of mental health, such as selfesteem: low ability individuals are the only ones to benefit significantly from college graduation in terms of self-esteem.

The literature on the effect of quality of schooling on health is more recent and much sparser despite addressing a topical policy issue: are long-term health returns obtained by simply extending years of education or the quality of that schooling also important? Johnson (2010) and Jones et al. (2011) show that attending different types of schools can have long-term effects on health and lifestyle, over and above the influence of years of 
schooling and academic qualifications attained. It should be noted that quality of schooling is defined in a broad sense, encompassing qualitative differences in schools' curricula, endowments of human and material resources, along with differences in the mix of pupils that may be associated with reference group and peer group effects.

This strand of research has looked mostly at mean effects of quality of schooling. We advance this literature by going beyond average impacts and by exploiting data from a policy intervention aimed at transforming the quality, rather than the length, of secondary education. We examine the role of heterogeneity in the health effect of quality of schooling, as well as to identify gainers and losers from the changes induced by the reform. In our work, quality of schooling is determined by the environment in which students get education. Specifically, we look at the impact of exposure to mixed ability schools in adolescence. We compare two alternative systems of schooling: one in which children took a test to determine whether they went to a more academic grammar school or a more vocational secondary modern school, and the other in which the test was abolished and all students, with varying abilities, attended comprehensive schools.

We use data from the National Child Development Study (NCDS). The NCDS follows a cohort of around 17,000 individuals from their birth in the week of $3^{\text {rd }}$ March 1958. The NCDS cohort-members went through secondary schooling during the 1970s and attended different types of school since their secondary schooling lay within the transition period of the comprehensive education reform that was implemented in England and Wales from the mid-1960s ${ }^{1}$. This reform restructured secondary education by replacing the former system of early tracking of students with a non-selective,

\footnotetext{
1 Comprehensive schooling was introduced in Scotland much earlier than in England and Wales, preventing the use of the Scottish sub-sample as an adequate comparison group for types of school and educational qualifications.
} 
comprehensive, educational system. Comprehensive schooling was not implemented simultaneously across the country, hence only some cohort members attended the selective system of state-funded education, which comprised grammar schools, secondary modern schools and a small number of technical schools. Among members of the NCDS cohort, 12 per cent attended grammar schools at age 16, 25 per cent attended secondary moderns and 57 per cent attended comprehensive schools. An additional 6 per cent attended private fee-paying schools, independent of the state educational system and reforms ${ }^{2}$.

These reforms have been evaluated in terms of their direct effect on educational attainment and subsequent impact on labour market outcomes (Kerkchoff et al., 1996; Jesson, 2000; Dearden et al., 2002; Galindo-Rueda and Vignoles, 2005). More recently, Pischke and Manning (2006) and Bonhomme and Sauder (2011) have raised concerns about the results from earlier evaluations by providing evidence that suggests that these did not account adequately for the effect of unobserved heterogeneity in the pupil composition of the two educational systems, as possibility parental selection into, or out of, the selective educational system. We draw on this literature and adopt a local instrumental variables approach to deal with the issue of potential endogeneity and recover the full distribution of the effect of quality of schooling on health and health related behaviors (Basu, 2014).

Our results indicate that there is substantial heterogeneity in the effects and significant persistence of these effects over time at the individual level. The newer comprehensive schooling system produced significant negative effects on long-term health and increased smoking among a fraction of individuals. However, the ATE and TT were quantitatively

\footnotetext{
2 This subsample is thus not used in our analysis.
} 
similar and statistically insignificant indicating that cognitive abilities, which was the major driver for selection in to comprehensive schools, did not moderate the effects. Analysing the PeT effects shows that individuals who had lower non-cognitive skills are most likely to be negatively affected in the long-run from exposure to mixed-ability schools. Our results also show that cigarette smoking could be an important transmission channel of the long-term impact on health outcomes.

\section{THE COMPREHENSIVE EDUCATION REFORM}

As Kerckhoff et al. (1996: 1-2) describe it, following the Second World War, a cycle of educational reforms was initiated in Western Europe. This was characterised by a strong conviction in the importance of educational expansion, and mounting dissatisfaction with the stratified systems of schooling that most countries had inherited. Countries such as Norway and Sweden, followed by France and Scotland, spearheaded a move away from older stratified systems and towards unified, fully inclusive, systems of comprehensive schooling. From the mid-1960s the comprehensive reorganisation tookoff in England and Wales, and aimed at promoting equal opportunity in society through an improvement of the quality of the schooling accessible to children from disadvantaged backgrounds. It replaced the selective educational system with a nonselective, comprehensive system of secondary schooling. This policy reform was implemented at different speeds at the local level: some local education authorities (LEAs) implemented it quickly, but others resisted the change. This gradual and uneven transition allowed the two systems to co-exist for a long period of time. The NCDS cohort entered state secondary schools at age 11 in 1969 and completed their compulsory schooling at age 16 in 1974; at that point 40 per cent of the cohort members still experienced the selective system, while the remaining 60 per cent attended comprehensive schools. 
Grammar schools were academically oriented state schools that provided teaching for the entire age range 11-18, and prepared pupils to go on to higher education. Admission into these schools was determined by an exam taken at age 11 (the 'Eleven Plus') ${ }^{3}$. Pupils whose examination score did not permit entry into a grammar school attended either secondary modern schools, which were less academically oriented and covered the ages 11-16 or, in a small minority of cases, vocational schools aimed at providing training and technical apprenticeships ${ }^{4}$. Grammar and secondary modern schools were significantly different in terms of their curricula, examinations and academic environment. They were also very different regarding other qualitative aspects. Among the schools attended at age 16 by the NCDS cohort members used in our analysis, 69 per cent of grammar schools were single sex, while only 13 per cent of comprehensive schools were single sex. Streaming of classes by academic ability was common in secondary modern schools (42 per cent) and comprehensive schools (39 per cent) but rare among grammar schools (17 per cent). Some comprehensive schools were former secondary moderns (26 per cent) or grammar schools (19 per cent), with the rest being newly created. Furthermore, the distribution of indicators of quality of the school, such as the pupil-teacher ratio and of the average number of expelled students, also differs across types of schools.

The issue of the relative advantages of early tracking versus late tracking of students in secondary schools remains a topical education policy issue ${ }^{5}$. The comprehensive reform continues to receive considerable attention in the social sciences. In the economic

\footnotetext{
3 As part of the comprehensive reform, the Eleven Plus was abolished as a national examination in England and Wales by the 1976 Education Act. Despite this, the selective system and the existence of grammar schools has persisted in certain areas, such as Kent.

${ }^{4}$ In a few cases, pupils whose CSE grades were sufficient transferred to grammar schools or sixth form colleges to complete their A-levels.

5 For example, the OECD evaluation of the results of the Programme for International Student Assessment (PISA) - OECD (2005) - devotes great attention to comparing the relative performance of national education systems with different degrees of selectivity.
} 
literature, Galindo-Rueda and Vignoles (2004) use the NCDS data to investigate the effects of the reform on educational outcomes. Since type of school attended by each cohort member may influenced by third factors, hence endogenous, they propose an instrumental variables identification strategy, relying on two main instruments: the share of comprehensive schools in a cohort-member's LEA and Conservative Party control of the cohort member's LEA (which the authors claim to be negatively correlated with the probability of attending a comprehensive school, but orthogonal to the educational outcomes). Pischke and Manning (2006) revisit this issue and question the main results of earlier work. They find that comprehensive areas were poorer and populated by children with lower ability than selective areas. Thus, the policy impacts on pupils' examinations scores, reported in the literature, are likely be influenced by observed and unobserved heterogeneity and, possibly, affected by selection bias. In addition, they also find that Conservative areas tended to be significantly richer and better educated than Labour ones, hence the validity of Conservative control of individuals' constituency as an instrument for the educational system attended is open to question. These concerns, with unobserved heterogeneity and selection, have been reinforced by Bonhomme and Sauder (2011). They model test scores as the output of a production function and use this model to generalise the difference-in-differences approach to identify the distribution of potential outcomes. Their results suggest that unobserved heterogeneity, which incorporates pupils' initial endowment of cognitive skills, is likely to be a key factor determining the differences in examination scores between pupils exposed to the selective and to the comprehensive system of education.

We draw on these concerns and examine more closely the plausibility of the different instrumental variable strategies proposed in earlier literature as a basis for our own 
identification strategy. In doing so we allow for heterogeneity in the treatment effects and estimate the full distribution of these effects.

\section{EMPIRICAL STRATEGY}

As shown by Conti et al. (2010, 2011), individual responses to different types of education are likely to be heterogeneous. In addition, in our case, it is possible that selection into comprehensive or selective schooling reflects these heterogeneous effects. Pischke and Manning (2006) allude to the possibility that the results from earlier literature on the comprehensive education reform are systematically biased due to the presence of essential heterogeneity.

To address these issues, we define a model of potential outcomes and treatment choice using the Neyman-Fisher-Cox-Rubin framework of potential outcomes. Consder two treatment regimes - comprehensive schools (treated) state denoted by $D=1$ and selective schools (untreated) denoted by $D=0$. The corresponding potential individual outcomes in these two states are denoted by $Y_{1}$ and $Y_{0}$. We assume:

$$
Y_{1}=\mu_{1}\left(X_{O}, X_{U}, \vartheta\right) \text { and } Y_{0}=\mu_{0}\left(X_{O}, X_{U}, \vartheta\right)
$$

where $X_{0}$ is a vector of observed random variables, $X_{U}$ is a vector of unobserved random variables which are also believed to influence treatment selection (they are the unobserved confounders) and $\vartheta$ is an unobserved random variable that capture all remaining unobserved random variables. $\left(X_{O}, X_{U}\right) \amalg \vartheta$ and $X_{O} \amalg X_{U}$ where $\amalg$ denotes statistical independence. 
Selection into treatment (prior to the realization of the outcome of interest) is determined by:

$$
D=1 \text { if } \mu_{D}\left(X_{0}, Z\right)-U_{D}>0
$$

where $Z$ is a (non-degenerate) vector of observed random variables (instruments) influencing the decision equation but not the potential outcome equations, $\mu_{D}$ is an unknown function of $X_{0}$ and $Z$, and $U_{D}$ is a random variable that is correlated with $X_{U}$ and all remaining unobserved random variables influencing choice. By definition, $\bigcup_{D} \amalg \vartheta$, which also defines the distinction between $X_{U}$ and $\vartheta$ in (1). Equations (1) and (2) represent the nonparametric models that conform to the Imbens and Angrist's (1994) independence and monotonicity assumptions needed to interpret instrumental variable estimates in a model of heterogeneous returns. As in Heckman and Vytlacil (1999) we can rewrite (2) as:

(3) $D=1 \quad$ if $P\left(X_{0}=x_{0}, Z=z\right)>V$

where $V=F_{U_{D}}\left[U_{D} \mid X_{O}=x_{O}, Z=z\right], P\left(x_{0}, z\right)=F_{U_{D} \mid X_{O}, Z}\left[\mu_{D}\left(x_{O}, z\right)\right]$ and $F$ represents a cumulative distribution function. Therefore, for any arbitrary distribution of $U_{D}$ conditional on $X_{O}$ and $Z$, by definition, $V \sim \operatorname{Unif}[0,1]$ conditional on $X_{O}$ and $Z$. Under regular IV assumptions, Heckman and Vytlacil (1999) show that Marginal Treatment Effects can be identified by:

(4) $\frac{\partial E_{\vartheta}\left(Y \mid X_{O}=x_{0}, Z=Z\right)}{\partial p}=E_{\vartheta}\left(\left(Y_{1}-Y_{0}\right) \mid X_{O}, V=v\right)=\operatorname{MTE}\left(x_{O}, V\right)$, 
where $Y=D Y_{1}+(1-D) Y_{0}$ is the observed outcomes and $v=P\left(x_{0}, z\right)$.

Basu (2014) extends the LIV methods to identify PeT effects, which, for persons who choose treatment, are defined by:

(5) $E_{X_{u} \mid X_{O}, P(Z), D} E_{\vartheta}\left(Y_{1}-Y_{0} \mid x_{O}, P(Z), D=1\right)=E\left(Y_{1}-Y_{0} \mid x_{O}, V<P(Z)\right)$

$$
=P(z)^{-1} \int_{0}^{P(z)} \operatorname{MTE}\left(x_{O}, v\right) d v .
$$

Similarly, conditional effect for a person who did not choose treatment is obtained by integrating MTEs over values of $V$ greater than $p$.

Conceptually, a PeT effect is a weighted version of MTEs. For any given individual, the PeT effect identifies the specific margins where that individual may belong given its individual values of $X_{O}, P(Z)$ and $D$. It then averages the MTEs over those margins, but not all as in CATE. Therefore, a PeT effect is basically the X-Z-conditional Effect on the Treated for persons undergoing treatment and is the X-Z-conditional Effect on the Untreated for persons not undergoing treatment. Further details can be found in Basu (2014).

\subsection{Identification}

Endogeneity, induced by unobserved factors influencing both the type of schooling experienced and the potential outcomes of interest, has been at the heart of the literature on comprehensive schooling since its inception. Galindo-Rueda and Vignoles (2005) suggest the existence of unobserved individual heterogeneity and of selection into types 
of schooling based on unobserved gains (essential heterogeneity). For example, areas subject to selective schooling may retain of a higher proportion of more able students if their parents perceive that they would be likely lose from going to a mixed school as the result of the reform. Galindo-Rueda and Vignoles (2005) propose instrumenting the type of schooling experienced using the political affiliation of the child's electoral constituency (an area that is geographically smaller than the unit of implementation of the reform, the Local Education Authority (LEA)). The rationale for this is grounded on the gradual and decentralised implementation of the reform: while Labour areas tended to shift swiftly towards comprehensive schooling, areas under the control of the Conservative Party tended to resist and delay the implementation of the reform.

As mentioned above, Pischke and Manning (2006) question the validity of the political affiliation as an instrument. They estimate the effect of attending the comprehensive schooling system on test scores administered at age 11 (i.e. before the policy reform) as a falsification test. They find large and statistically significant effects, thereby disputing the validity of the political affiliation instrument. The NCDS includes another variable that has also been used in earlier literature as an instrument to evaluate the reform: the percentage of comprehensive schools in each individual's Local Education Authority in 1974. Nonetheless, the transition into either the selective or the comprehensive systems of schooling takes place in 1969, when cohort members were 11 years of age, rather than in 1974. In order to use an instrument that adequately reflects the context of this schooling transition we compiled data on the density of comprehensive schools by LEA, published in the 1969 Statistics of Education for England and Wales (Department of Education and Science, 1971). To assess the validity of this instrument we adapt the falsification test proposed by Pischke and Manning (2006) to the analysis of health outcomes and estimate the impact of comprehensive schooling on probability of cohort- 
members suffering from at least four childhood morbidities at age 11 using the 1969 percentage of comprehensive schools in the LEA as an instrument.

\subsection{Estimation}

In order to estimate the impact of the comprehensive school system and the individual heterogeneity in these effects, we use local instrumental variable methods (LIV) to compute person-centered treatment (PeT) effects (Heckman and Vytlacil 1999; Basu 2014).

To estimate Pe'T effects, we follow the following algorithm (Basu, 2014):

1. Run the first stage by regressing the indicator for comprehensive system (D) against observed factors $\left(X_{O}\right)$ and the instrument $(Z)$ using a probit model and predict the propensity score, $\hat{p}\left(x_{O}, z\right)$, for every individual.

2. Ensure that $\hat{p}\left(x_{O}, \boldsymbol{Z}\right)$ has mass at every value (rounded to 0.01) under both comprehensive and selective school systems, dropping any observations that do not.

3. Denote $\min p=\min \left\{\hat{p}\left(x_{O}, z\right)\right\}$ and $\operatorname{maxp}=\max \left\{\hat{p}\left(x_{O}, z\right)\right\}$

4. Run the second stage LIV estimand for each binary outcome $Y$ using a probit model with the following specification (determined by a series of goodness of fit tests): $Y=$ $\Phi\left(\alpha_{0}+\alpha_{1} \cdot X_{O}+\alpha_{2} \cdot \hat{p}+\alpha_{3} \cdot \hat{p} \cdot X_{O}+\alpha_{4} \cdot \hat{p}^{2}\right)$, where $\Phi$ is the cumulative normal distribution function.

5. Numerical integration: For each individual i:

a. Draw 1000 replications of $\mathrm{u} \sim$ Uniform[minp, maxp] 
b. Compute $d \hat{\Phi}(.) / d \hat{p}$ and evaluated it by replacing $\hat{p}\left(x_{O}, z\right)$ with each value of $u$. So there are 1000 values of $d \hat{\Phi}(.) / d \hat{p}$ for each individual $i$.

c. Compute $\mathrm{D}^{*}=\Phi^{-1}\left(\hat{p}\left(x_{O}, \boldsymbol{Z}\right)\right)+\Phi^{-1}(1-u)$ also generating 1000 values for each individual i.

d. Compute the PeT by averaging $d \hat{\Phi}(.) / d \hat{p}$ over values of $\mathrm{u}$ for which $\left(\mathrm{D}^{*}>0\right)$ if $\mathrm{D}=1$, otherwise, by averaging $d \hat{\Phi}(.) / d \hat{p}$ over values of $\mathrm{u}$ for which $\left(\mathrm{D}^{*} \leq 0\right)$ if $\mathrm{D}=0$.

6. Estimated PeT effects provide individualized effects of treatment effects. Mean treatment effect parameters are computed: averaging Pe'Ts over all observation gave ATE, averaging PeTs over over $\mathrm{D}=1$ or $\mathrm{D}=0$ gives the TT and TUT respectively.

We estimate the Pe'T effects of experiencing comprehensive schooling compared to the selective schooling system on health outcomes (indicators for self-reported excellent health, malaise and long standing illness) and cigarette smoking (indicator for current smoking) at ages 23, 33 and 42 years separately. We use the estimated PeT effects to study the following:

1. Differential drop-out: We compared whether there are systematic differences in the distribution of Pe'T effects at age 23 between those who would continue to participate at age 33 versus those who would drop out before age 33. Similarly, we looked at Pe'T effects at age 33 based on drop-out behaviors by age 42 .

2. Time dependence of effects: We explored the dependence of PeT effects at age 42 to those of the same individuals at age 23 in order to study the time dependence of effects.

4. Effects on multi-dimensional outcomes: We compared the dependence amongst the PeT effects of malaise versus long standing illness for the same individuals in 
order to study the multi-dimensional effects of alternative schooling systems. We also repeated similar analysis between the effects on smoking at age 33 years and malaise at age 42 years in order to establish a potential channel through which alternative schooling systems may effect outcomes.

5. Heterogeneity: We studied how the average effects on outcomes among those who did not attend comprehensive schooling systems differed between those who attended secondary modern schools versus grammar schools. This comparison helps to illustrate if exposure to comprehensive schools would have had differential effects on students who went to the different types of schools within the selective system.

6. Finally, we develop a prediction algorithm based on individual factors that predict significant Pe'T effects on malaise and long-standing illness at age 42.

\section{DATA}

Members of the National Child Development Study (NCDS) cohort are followed from birth, in the week of $3^{\text {rd }}$ March 1958. In the early waves of the Study information was obtained from parents, medical examinations, tests of ability and from the child's school; extensive data are thus available on the cohort-members' childhood health, parental background, and educational achievement. The subsequent waves include self-reported information on social status in adulthood, health-related behavior and a wide range of health outcomes.

Our empirical strategy aims at identifying the impact of educational attainment and of the characteristics of secondary schooling experienced by members of the 1958 cohort on adult health and health-related behaviors after controlling for a broad set of pre- 
treatment factors ${ }^{6}$. These include measures of family socioeconomic status and the local environment during early childhood; measures of childhood health and use of health care and health within the family; and measures of cognitive and non-cognitive skills and social adjustment of the child. Because the comprehensive reform was a secondary education policy, we also condition on characteristics of the individual's primary education, which, in our case, constitute pre-treatment factors. The specific variables used are described below and listed in Table A.1 in the Appendix.

\subsection{Pre-treatment factors}

\section{Childhood bealth, genetic endowments and family background}

The NCDS includes extensive information on the childhood characteristics that were shown to be key predictors of health and lifestyle in adulthood in studies such as Case et al. (2005) and Currie and Stabile (2004). Following Power and Peckham (1987), we create morbidity indices by aggregating twelve categories of health conditions, that affect the child at ages 7 and 11 . We complement this with indicator variables for the occurrence of diabetes, epilepsy and other chronic conditions among parents and siblings, in order to account for hereditary conditions in the cohort member's family. Following Carneiro et al. (2007), parental socioeconomic background is proxied by the occupational social class and the years of schooling of cohort members' father. Following Case et al. (2005) and Lindeboom et al. (2009), we augment this characterisation using data on the incidence of household financial difficulties during the cohort member's childhood and adolescence.

\section{Local area characteristics}

Rich information about the cohort members' immediate milieu is available and aggregated at different geographic levels, allowing a detailed demographic and

${ }^{6}$ As noted by Dearden et al. (2002), these reflect early life circumstances, occur prior to secondary schooling, and are not influenced by subsequent educational choices. 
socioeconomic characterisation of each individual's local area: electoral constituency level, local education authority level and census enumeration district level (the smallest unit for which census statistics were then available, with an average population of about $500)^{7}$. Available variables include the percentage of the local population who are unemployed or long-term sick, working women, employed in particular sectors (manufacturing and agricultural), who are in different occupational groups (professional/managerial, other non-manual, skilled manual, semi-skilled, unskilled), owner occupiers, council tenants, non-whites, and immigrants (see Dearden et al., 2002; Galindo-Rueda and Vignoles, 2004; Pischke and Manning, 2006).

\section{Cognitive ability and socio-emotional development}

Cognitive skills, socio-emotional development and personality traits have received growing attention in the literature on human capability formation. In particular, these factors were shown to be key determinants of health and health-related behaviors in recent papers such as Carneiro et al., (2007), Keastner (2009) Conti et al. (2010, 2011). The NCDS provides measures of early cognitive ability and social development collected before respondents began their secondary schooling. Scores of ability tests taken at age 7 and 11 are available on a series of cognitive dimensions: mathematics, reading, copying designs and general ability. These test scores are highly correlated at the individual level leading to multicollinearity. To avoid this, we follow Galindo-Rueda and Vignoles (2005) and use principal components analysis to construct a single measure of cognitive ability using the first principal component ${ }^{8}$.

\footnotetext{
7 These small area data are available for the years 1971 and 1981 under a special licence, which imposes restrictions on the handling and usage of the data.

8 At age 11, the first principal component accounts for 85 per cent of the joint variation and, strikingly, the weights attached to the three dimensions $-0.583,0.567$ and 0.582 - are virtually identical.
} 
Serendipitously, the three dimensions of cognitive ability used to construct our index mathematics, reading and general ability - along with the fact that the index derived from the first principal component gives equal weight to each dimension, mirrors the three elements of the Eleven Plus examination. Cognitive ability score at age 11 can thus be interpreted as a proxy for performance in the Eleven Plus for those who took the examination.

We draw on Carneiro et al. (2007) and use the score for the Bristol Social Adjustment Guide (BSAG) as our measure of early social development. This is a measure of problems with social adjustment at age 11: teachers were asked to report whether the child had problems in twelve behavioral domains such as hostility towards children and adults, anxiety, withdrawal, 'writing off adults, unforthcomingness, depression, restlessness, acceptance by adults, inconsequential behavior, and other psychological and nervous symptoms (Stott, 1987). One point is attributed to each positive answer; points are then summed to obtain the BSAG social maladjustment score.

\subsection{Educational attainment and quality of schooling}

Detailed information on the cohort-members' educational attainment is available in the NCDS. In order to exploit this wealth of data we build a measure of attainment in secondary education with thirteen categories, ordered according to the grades obtained and number of passes 9 . In our empirical analysis we use a simple 0-12 scaling of this variable as a parsimonious measure of educational attainment, although we have also used models with dummy variables for each category to check the robustness of the results.

${ }^{9}$ This is variable 'E386' in the NCDS data dictionary; this information was collected in the 1978 Survey of Public Exams, based on a questionnaire sent to the school attended by NCDS respondents at wave 3 . 
Quality of schooling is captured by two sets of variables. First, as described in Section 1, the NCDS cohort-members attended different types of schools; this is captured by indicators of the school attended at age 16: secondary modern, grammar, and comprehensive. Second, we use information on characteristics of the school, which have been widely used as standard proxies of quality of schooling in applied work on education and labour (see, for example, Dearden et al., 2002). These include the teacher/pupil ratio, the ratio of expelled pupils to the total number, and indicators of whether the school was single sex and whether classes were streamed by ability.

Finally, we control for information about the individuals' primary schooling and parental aspirations for their child. This includes the number of children in the child's primary school class at age 7 in 1965, whether parents reported that their child was unhappy at school in 1965, and an indicator for whether parents wished their child to continue beyond the minimum school leaving age.

\subsection{Outcomes: health and health-related behaviors}

Information on the particular medical condition associated with the long-standing illness is available and classified according to the International Classification of Diseases (ICD10). The most prevalent conditions are illnesses of the musculoskeletal system (25.7 per cent), circulatory system (11.8 per cent), respiratory system (11.4 per cent) and metabolic problems ( 9.5 per cent), of which 70 per cent suffer from diabetes.

We also take into account mental illness in adulthood. Respondents answer to a series of questions from the Cornell Medical Index Questionnaire, each targeting a particular mental ailment. The number of positive answers given is then used as a malaise score along the lines of Carneiro et al. (2007). The malaise score is a measure of psychiatric 
morbidity (with a special focus on depression), developed at the Institute of Psychiatry from the Cornell Medical Index (Rutter et al., 1970). The NCDS team suggest the use of a severity scale: individuals are considered normal if they score between 0 and 7 points and depressed if they score between 8 and 24 points (Rodgers et al., 1999). In our analysis we use this scale to define an indicator variable that takes the value 1 if individuals are depressed (malaise score above 7) and zero otherwise.

The NCDS also documents some of important health-related behaviors. The Study includes self-reported information on the number of cigarettes smoked per day. These data are only available once respondents are aged 23 and above.

\section{RESULTS}

\subsection{Sample selection, missing values and attrition}

Table 1 shows our sample selection and the number of observations lost due to various exclusion criteria. Some NCDS cohort members are excluded from our estimation sample because they attended private schools, which are independent from state education and schooling reforms.

\section{- Insert Table 1 here -}

More significantly, a large number of observations is lost due to item non-response to parts of the questionnaire that are essential for our analysis or because at some stage they have attrited out of the NCDS. This is the most important cause of sample size reduction in the economics literature that uses the NCDS. This is acknowledged in several papers that feature sample sizes comparable to ours (Dearden et al., 2002; Galindo-Rueda and Vignoles, 2004, 2005; Pischke and Manning, 2006, Lindeboom et al., 2009; Jones et al., 2011). The degree, and repercussions, of non-random attrition has been extensively examined in this earlier literature, which concludes it does not constitute 
a serious source of bias (for example, Plewlis et al., 2004; Case et al., 2005 and Lindeboom et al., 2009). Table 2 shows, in the case of our analysis, the comparison between included and excluded observations. The difference in means for most covariates is small and statistically insignificant, with a few notable exceptions. Individuals included in our estimation sample tend to exhibit higher levels of cognitive and non-cognitive ability, to live in slightly more affluent areas and to be less likely to have experienced financial hardship in childhood. In light of these disparities, where possible we disaggregate our key estimation results for included and excluded observations in the following sections.

\section{- Insert Table 2 bere -}

It is also informative to compare the mean differences in covariates between the cohort members in our treatment and control groups; these are reported in Table 3. Average ability scores are higher amongst selective system pupils, when compared with their comprehensive counterparts. This difference is also identified in Pischke and Manning (2006), thereby substantiating their concerns with unobserved factors and parental selection of the best pupils into the selective system. In addition, similarly to Pischke and Manning (2006), Table 3 shows that selective areas tend to be slightly more affluent than comprehensive ones. Importantly, however, Table 3 also shows that these differences are almost entirely eliminated across the median of our instrument; this balancing of observed covariates over the distribution of the instrument is reassuring of its ability to deal with the issues of selection and unobserved heterogeneity.

\section{- Insert Table 3 here -}

In addition, our IV is not rejected by the falsification test. As suggested by Pischke and Manning (2006), we estimate the impact of comprehensive school on the probability of suffering from at least four childhood morbidities at age 11. The estimated ATE, TT and TUT from this placebo regression approach are $-0.01(0.08),-0.001(0.09)$ and -0.02 (0.07) and are not statistically significant. 


\subsection{First stage regression results}

Table A.4 (in the Appendix) reports the results of the first stage regression: where we regress the indicator for comprehensive system (D) against observed factors (X) and the instrument $(Z)$ using a probit model. The results show that the percentage of the cohortmember's LEA that is comprehensive in 1969 is a strong and statistically significant predictor of the member's schooling system. As explained in Section 2.3, we then predict the propensity score $\hat{p}(x, z)$ for each individual. Figure 1 shows the distribution of the values of the propensity score amongst treated and untreated observations. Clearly, $\hat{p}(x, z)$ has mass at almost every value (rounded to 0.01) under both schooling systems there are only 20 individuals off the common support, which are dropped before running the second-stage regression.

\section{- Insert Figure 1 bere -}

\subsection{Second stage regression results: health outcomes}

We examine the effect of experiencing the comprehensive schooling system on our outcomes of interest, at three different points of the life-cycle: ages 23,33 and 42 . We also focus on retrieving three causal parameters: the average treatment effect (ATE), the treatment effect on the treated (TT) and the treatment effect on the untreated (TUT). Table 4 shows the effect of comprehensive schooling on the probability of cohort members suffering from depression. The comparison between TT and TUT suggests that, while this effect is large and positive in the long run (ages 33 and 42), individuals who attended the comprehensive school system experienced no impact, or even a mild negative effect in the short run (age 23). 
Our results suggest that the long-term impacts of schooling are not necessarily related with exam performance; they can be non-academic, such as an improvement in selfesteem, or, more generally, mental health. Interestingly, these results are also in line with new evidence brought to the fore in Heckman et al. (2014) regarding the effect of educational choices on key domains of mental health. Graduating from college improves self-esteem very significantly, but only for low-ability types. Their results also indicate that it is the educational pathways (rather than the highest qualifications attained) that has long-run health effects. Thus, our results suggest that selection into or out of qualitatively different schooling systems is likely to be one of these pathways, one of the channels through which education has short and longer-run health effects. We examine this possibility in greater detail in the following sections.

\section{- Insert Table 4 bere -}

As identified in Section 4.1, a significant number of observations are lost due to attrition and there are discrepancies between the mean values of some important covariates for included and excluded observations. Figure 2(a) shows our treatment effects, at different ages, for these two groups of observations. The distribution of these effects is markedly more compressed at age 33, when attrition begins to slow down, than at age 23. Nonetheless, these distributional differences do not deviate from the general pattern, of a null or slightly beneficial effect at age 23 , followed by a clear detrimental impact at age 42.

\section{- Insert Figure 2 bere -}

This pattern of effects is corroborated in the case of the probability of cohort-members reporting excellent health at ages 23, 33 and 42. As shown in Figure 2(b), this effect follows the same lifecycle trajectory identified for depression: attendance of 
comprehensive schooling has a mildly beneficial effect at age 23 , but this drops at age 33 and becomes clearly negative by age 42 .

Figure 2(c) shows the estimated treatment effects of the attendance of comprehensive schooling on the probability of cohort members suffering from a chronic condition at ages 23, 33 and 42. Although our estimates are not statistically significant, the effect of comprehensive schooling is mildly detrimental throughout the lifecycle.

\subsection{Selecting into and out of selection: identifying gainers and losers}

Unobserved heterogeneity is likely to influence selection into distinct educational paths, which, in turn, affect health-related outcomes and behaviors throughout the lifecyle. The person-centred treatment effects approach can be used to identify the cohort-members who gain and lose out from selection into a particular schooling system. This is shown in Figure 3, which illustrates the dependence between PeT effects of comprehensive schooling on the probability of depression at ages 23 and 42. The agglomeration of treatment effects in the top-right quadrant indicates that the individuals who, at age 23, suffer a detrimental effect from having attended the comprehensive system are also those who suffer a detrimental effect at age 42 .

- Insert Figure 3 bere -

Heckman et al. (2014) find that the positive effect of choices regarding length of schooling (for example the completion of a higher education degree) on mental health is typically concentrated amongst individuals with relatively lower cognitive ability. Our findings suggest that this concentration of mental health gains (and losses) appears to also hold in the case of quality, rather than length, of schooling. Figure 4 shows the PeT effects of comprehensive schooling on untreated individuals, i.e. those who experienced 
the selective system of education. Interestingly, the mental health losses associated with comprehensive schooling would be similar amongst cohort-members who actually attended secondary modern schools (the less academically intensive schools) or the grammar schools, highlighting that cognitive abilities that distinguishes these two group of student may not be a driving factor for these effects.

- Insert Figure 4 bere -

\subsection{Decomposition of the variance of Pe'T effects on the probability of depression}

In order to identify the factors driving the variance in Pet Effects on depression at age 42, we focus on two approaches: 1) a Variance decomposition approach that estimates how much of the overall variation in the PeT effects are driven by each baseline factor. 2) A stepwise backward logistic regression approach, with very conservative inclusion criteria of $\mathrm{p}$-value $<0.0001$, to identify the group of baseline factors that are most influential in predicting the individuals for whom comprehensive school would have significantly increased in probability of depression by age 42 .

\section{- Insert Table 5 here -}

The variance decomposition results are shown in Table 5. Factors explaining at least 5\% of the variance in the PeT effects on depression at age 42 are highlighted. Both cognitive and non-cognitive scores in childhood are identified in this list. However, when we focus only on those individuals who would be significantly hurt due to exposure to mixed ability schools, the factors most influencing in identifying these individuals do not include cognitive ability (Table 6). However, children with one point increase in their social adjustment scores are at a $10 \%$ greater risk of a significant increase in the probability of depression at age 42 .

- Insert Table 6 bere - 


\subsection{Transmission channels: quality of schooling, cigarette smoking and health}

The design of economic policy requires the identification of the channels through which quality of schooling affects health outcomes, at different stages in life. Earlier literature (see Jones et al., 2011 and references therein) suggests that the adoption of health-related lifestyles may be an important transmission mechanism of the health effects of education policy. To explore this we estimate PeT treatment effects of comprehensive schooling on the probability of cohort members reporting smoking at ages 23, 33 and 46. These estimates are shown in Table 7 and in Figure 1(d): the mean effects of comprehensive schooling are positive at all ages and particularly large, at ages 23 and 33.

\section{- Insert Table 7 here -}

Our results also indicate that the cohort-members for whom PeT effect are the highest at age 23 , are also the ones who are most seriously affected in terms of their physical health at age 42. This is illustrated in Figure 4: the concentration of Pe'T effects in the first quadrant suggests that positive PeT effects of comprehensive schooling on smoking track higher probabilities of suffering from a long-standing illness at age 42. This corroborates the role of cigarette smoking as a transmission mechanism of the impact of quality of schooling on health outcomes.

\section{DISCUSSION}

The health gradient by levels of education is a well established empirical regularity. Nonetheless, a growing body of recent evidence indicates that the positive association between education and long-term health outcomes can be decisively affected by the roles of selection and unobserved heterogeneity. Conti et al. $(2010,2011)$ and Heckman et al. 
(2014) use data from British and US longitudinal studies to unveil the full distribution of the health returns to different levels of schooling. They provide solid evidence showing that the effect schooling on health-related behaviors and outcomes varies considerably between different levels of schooling and depends crucially on individual characteristics. The health returns to different lengths of schooling are thus likely to exhibit considerable heterogeneity that needs to be taken into account in the design of policy interventions.

We follow this strand of research and use data from a British longitudinal study to examine whether heterogeneity is also an important feature of the health returns to qualitatively different types of edcation. We obtain identification from a large natural experiment that affected qualitative aspects of schooling, most specifically a mixed ability environment but also encompassing schools' curricula, endowments of human and material resources. We adopt a local instrumental variables and estimate person-centred treatment effects of different types of schooling, thereby recovering the distribution of its effect on health and health-related behaviors at different stages of the lifecycle.

Our results indicate that the average impacts of exposure to comprehensive schools compared to a selective schooling system in adolescence led to - 1) increased smoking prevalence that peaks at age 33 and 2) increase probability of depression at ages 33 and 42. However, the average effects are not statistically significant. In fact we do not see differences in the average treatment effect and the effect of the treated, where selection into comprehensive schools was driven primarily cognitive ability levels. However, we do find considerable variation in individual treatments effects (in line with Heckman et al. 2014) and the magnitude of these effects are persistent within individuals as they age. We find that if all children in the NCDS cohort were sent to comprehensive schools, about $50 \%$ of them would have significant increases in the probabilities of long-standing illness or 
depression at some point in their adulthood (up to age 42). Those who would be significantly worse off on depression score at age 42 due to comprehensive schools are more likely to be men and those who had lower non-cognitive abilities at age 11 .

Finally, our results also show that the attendence of comprehensive schooling has strong positive impacts on the probability of individuals being cigarette smokers later in life. This confirms the role of smoking as leading transmission channel of the long-term impact of type of schooling on health outcomes for this cohort. 


\section{REFERENCES}

Basu A. 2014. "Person-Centered Treatment (PeT) effects using instrumental variables: An application to evaluating prostate cancer treatments." Journal of Applied Econometrics 29:671-691.

Bonhomme, S. and Sauders, U. 2011. "Recovering distributions in difference-indifferences models: a comparison of selective and comprehensive schooling." Review of Economics and Statistics, 93(2): 479 - 494.

Case, A. Fertig, A. and Paxon, C. 2005. "The lasting impact of childhood health and circumstance." Journal of Health Economics, 24: 365-389.

Carneiro, P. Crawford, C. and Goodman, A. 2007. "The impact of cognitive and noncognitive skills on later outcomes." CEE Discussion Papers.

Conti, G., Heckman, J. and Urzúa, S. 2010. "The Education-Health Gradient” American Economic Review 100(2), pp. 234-38.

Conti, G., Heckman, J. and Urzúa, S. 2011. "Early endowments, education and health". Human Capital and Economic Opportunity Working Group Working paper 2011011 University of Chicago.

Cunha, F. and Heckman, J. 2007. "The Technology of Skill Formation." American Economic Review 97(2), pp. 31-47.

Cunha, F. and Heckman, J. 2008. "Formulating, identifying and estimating the technology of cognitive and noncognitive skill formation." Journal of Human Resources

Cunha, F., J. Heckman, J. and Schennach, S. 2010 "Estimating the Technology of Cognitive and Noncognitive Skill Formation”, Econometrica 78(3), p.p. 883-931.

Currie, J. and Moretti, E. 2003. "Mother's education and the intergenerational transmission of human capital: evidence from college openings." Quarterly Journal of Economics, 118:1495-1532.

Currie, J. Stabile, M. 2004. "Socioeconomic status and health: why is the relationship stronger for older children?” American Economic Review 93: 1813-1823.

Department of Education and Science 1971. "Statistics of Education - 1969", Her Majesty's Stationary Office, London.

Dearden, L. Ferri, J. And Meghir, C. 2002. "The effect of school quality on educational attainment and wages." Review of Economics and Statistics. 84:1-20.

Galindo-Rueda, F. and Vignoles, A. 2004. "The heterogeneous effect of selection in secondary schools: understanding the changing role of ability", IZA Discussion Paper No. 1245.

Galindo-Rueda, F. and Vignoles, A. 2005. "The declining relative importance of ability in predicting educational attainment." Journal of Human Resources, 40: 335-353 
Grimard, F. and Parent, D. 2007. "Education and smoking: Were Vietnam War draft avoiders also more likely to avoid smoking?" Journal of Health Economics, 26: 896-926.

Heckman, J.J., Humphries, J.E., Veramendi, G. and Urzúa, S. 2014. "Education, health and wages". NBER working paper 19971.

Heckman, J.J., Urzúa, S. and Vytlacil, E. 2006 "Understanding instrumental variables in models with essential heterogeneity" Review of Economics and Statistics, 88(3): 389-432.

Heckman, J.J., and Vytlacil E.J. 1999. Local instrumental variables and latent variable models for identifying and bounding treatment effects. Proceedings of the National Academy of Sciences, 96(8): 4730-34.

Imbens G. and Angrist J. 1994. Identification and estimation of local average treatment effects. Econometrica, 62(2): 467-475.

Jesson, D. 2000. "The comparative evaluation of GCSE value-added performance by type of school and LEA." University of York discussion paper No. 2000/52.

Johnson, R. 2010 "The Health Returns to Education Policies: From Preschool to High School \& Beyond" American Economic Review, 188-94.

Jones A.M., Rice, N. and Rosa Dias, P. 2011. "Long-term effects of cognitive skills, social adjustment and schooling on health and lifestyle: evidence from a reform of selective schooling". Journal of Human Capital 5(3) 342-76.

Keastner, R. 2009. "Adolescent cognitive and non-cognitive correlates of adult health." Technical report, National Bureau of Economic Research.

Kenkel, D., Lillard, D. and Mathios, A. 2006. "The roles of high school completion and GED receipt in smoking and obesity", Journal of Labour Economics, 24: 635-660.

Kerkchoff, A.C. Fogelman, K., Crook, D. and Reeder, D. 1996. "Going comprehensive in England and Wales: A Study of Uneven Change." London: The Woburn Press.

Lindeboom, M., Llena-Nozal, A. and Van der Klaauw, B. 2009. "Parental education and child health: evidence from a schooling reform." Journal of Health Economics, vol. 28, pp. 109-131.

Lleras-Muney, A. 2005. "The relationship between education and adult mortality in the United States.” Review of Economic Studies, vol. 72, pp. 189-221.

Oreopoulos, P. 2006. "Estimating average and local average treatment effects of education when compulsory schooling laws really matter." American Economic Review, vol. 96, pp. 152-175.

Pischke, S. and Manning, A. 2006. "Comprehensive versus selective schooling in England and Wales: what do we know?” IZA DP No. 2072. 
Plewis, I. and Calderwood, L. et al. 2004. "Changes in the NCDS and BCS70 populations and samples over time”. London, Centre for Longitudinal Studies.

Power, C. and Peckham, C. 1987. "Childhood morbidity and adult ill-health" National Child Development Study User Support Working Paper No. 37.

Rodgers, B., Pickles, A., Power, C., Collishaw, S. and Maughan, B. 1999 "Validity of the Malaise Inventory in general population samples." Social Psychiatry and Psychiatric Epidemiology, vol. 34, pp.333-341.

Rutter, M., Tizard, J. and Whitemore K. 1970. "Education, Health and Behaviour", London.

Silles, M. 2009. "The causal effect of education on health: evidence from the United Kingdom”, Economics of Education Review, vol. 28, pp. 122-128.

Stott D. H. 1987. "The social adjustment of children: Manual to the Bristol Social Adjustment Guides.” London: Hodder and Stoughton

Van Kippersluis, H., O. O'Donnell, and E. van Doorslaer (2011). "Long Run Returns to Education: Does Schooling Lead to an Extended Old Age?" Journal of Human Resources 46(4): 695-721. 
Figure1: Distribution of the propensity score $P(X, Z)$ : observations within and off common support

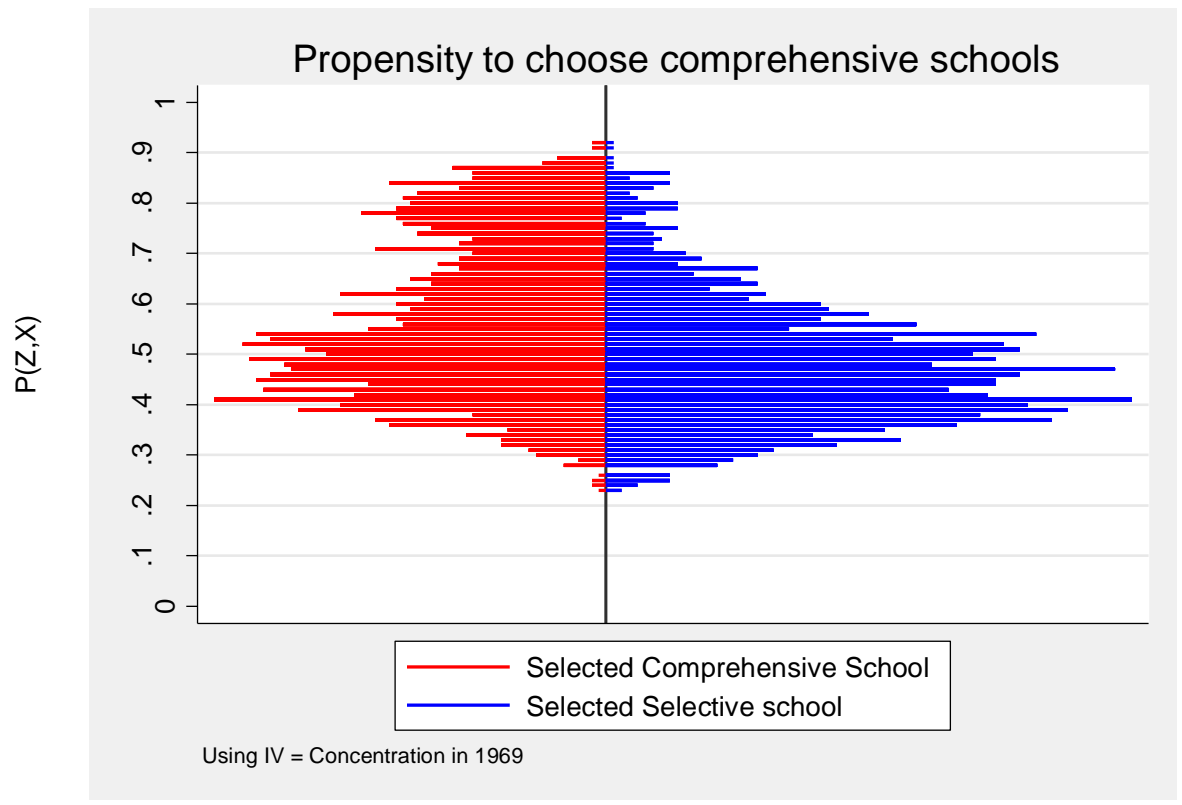


Figure 2: Person-centered Treatment $(\mathrm{Pe} T)$ effects over time.

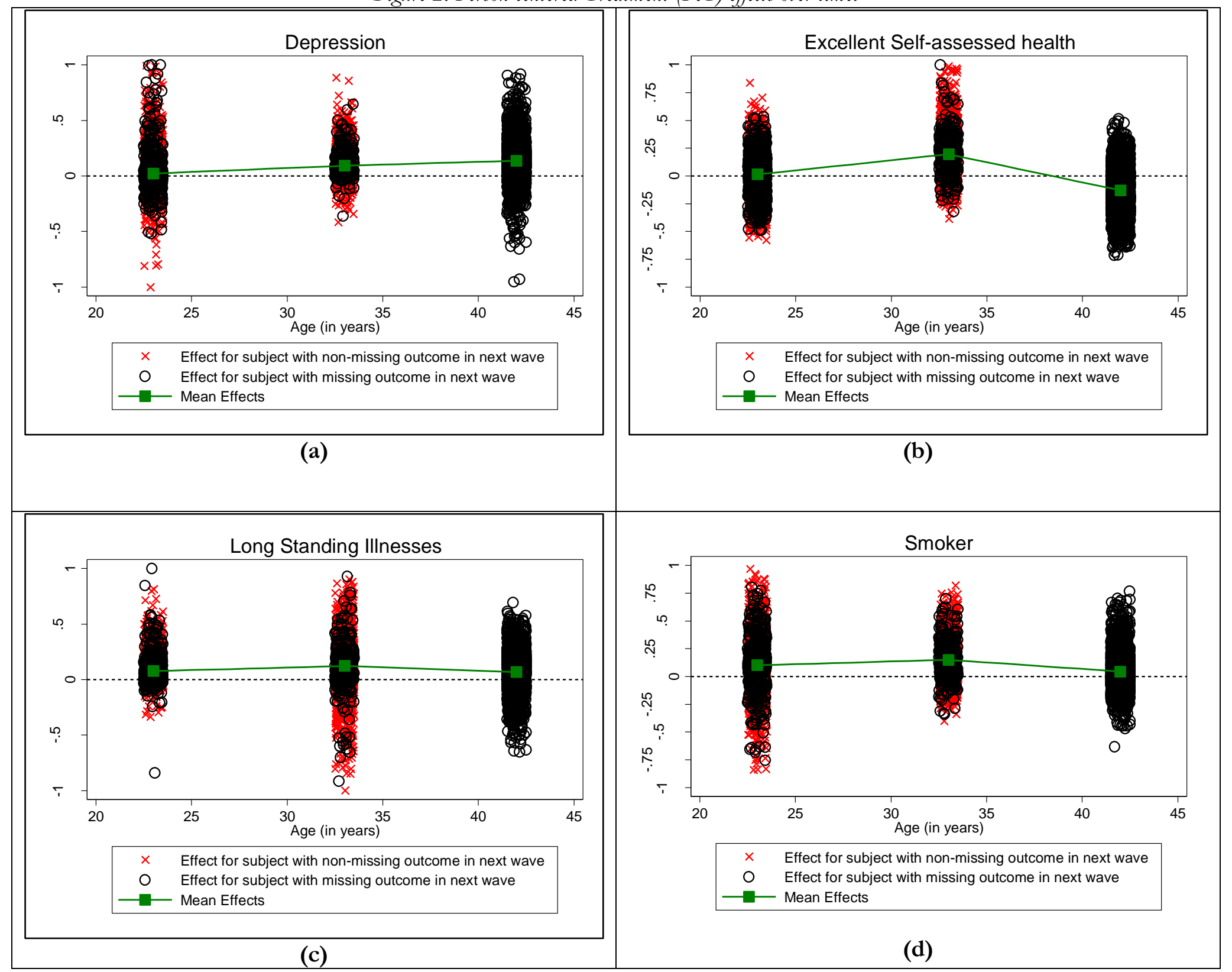


Figure 3: Dependence between PeT effects of comprehensive schooling on depression at ages 23 (horizontal axis) and 42 (vertical axis)

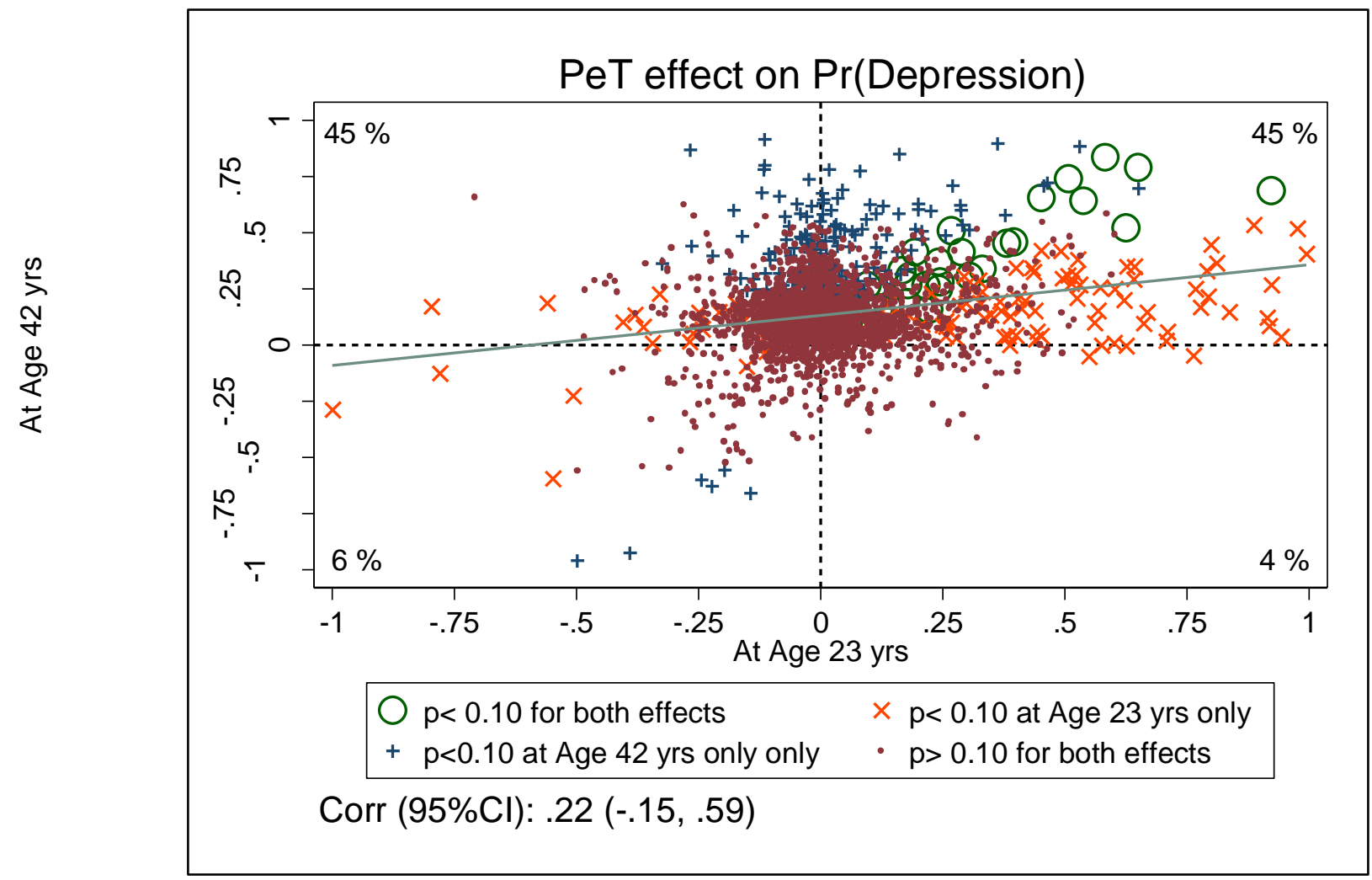


Figure 4: PeT effects of comprehensive schooling on the untreated (i.e. cohort-members who did not attend comprehensive schools)

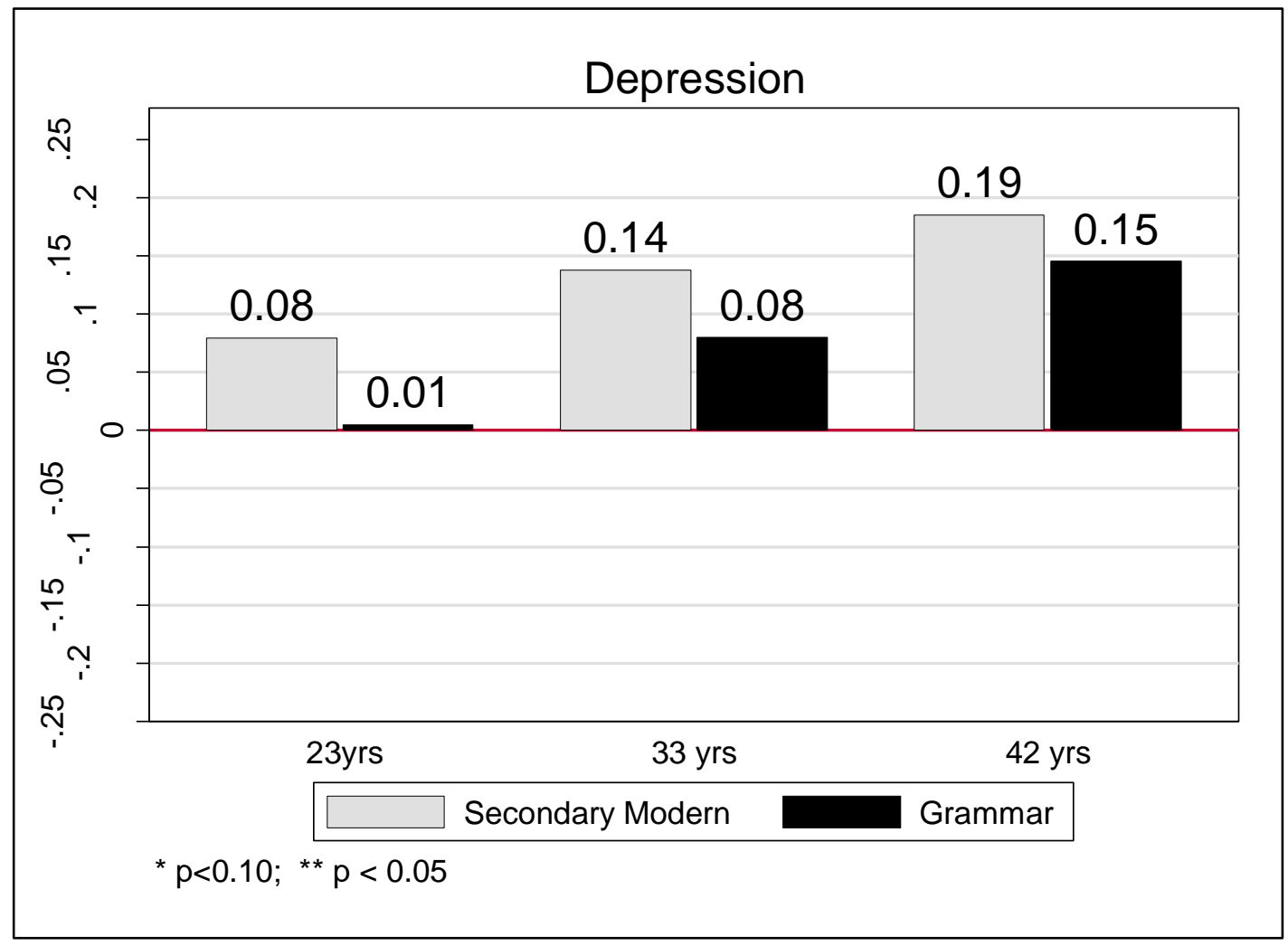


Figure 5: Dependence between PeT effects of comprehensive schooling on cigarette smoking at age 23 (horizontal axis) and probability of long-standing illness at age 42 (vertical axis)

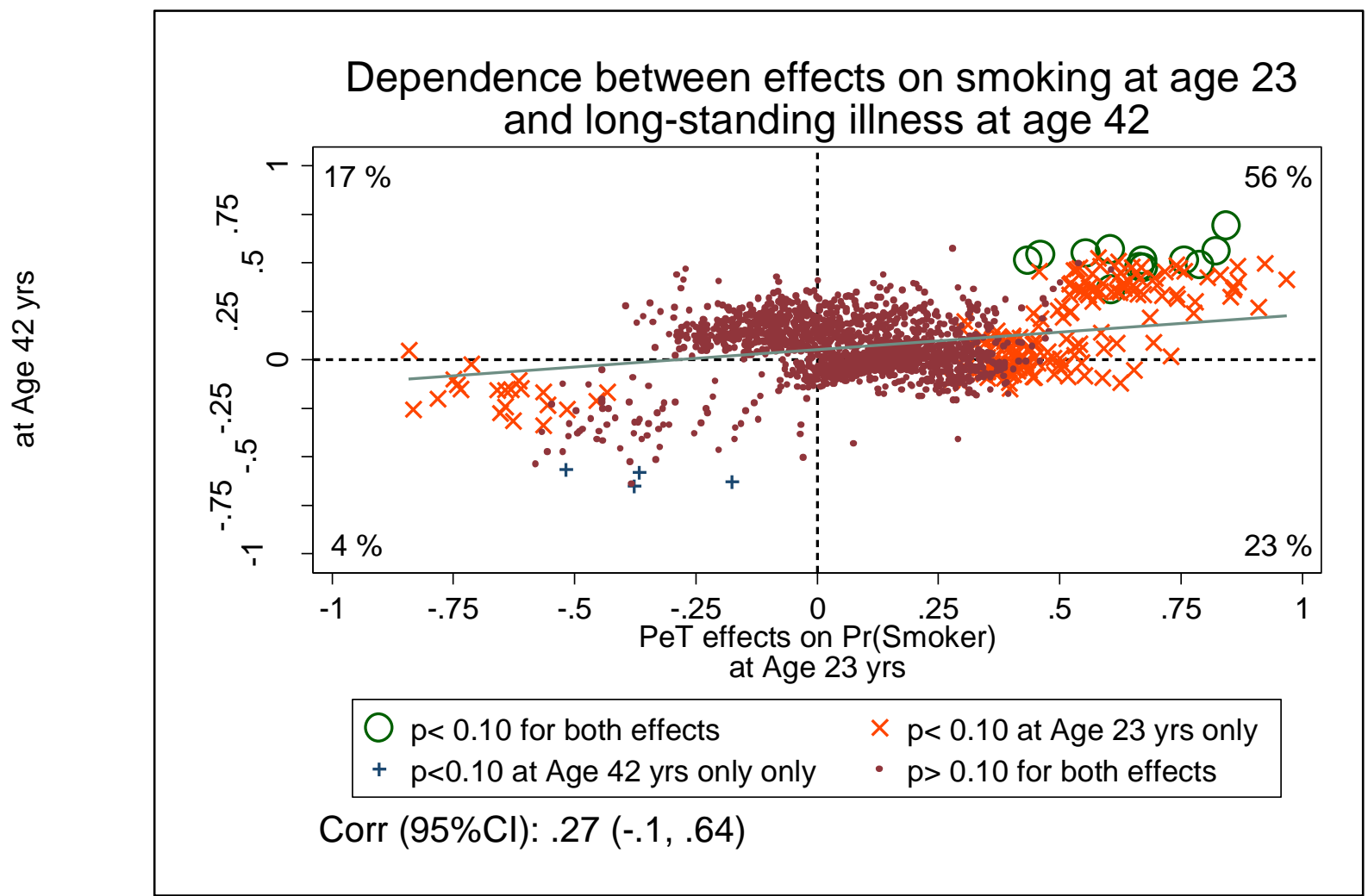


Table 1: Sample selection, missing values and attrition

\begin{tabular}{l|c|c}
\hline Criteria & Excluded & Total \\
\hline Total subjects in NCDS Cohort at Age 16 years & 706 & 16338 \\
$\begin{array}{l}\text { Private Schools } \\
\text { Comprehensive school penetration rate }>80^{\text {th }} \text { percentile }\end{array}$ & 2251 & 13381 \\
\hline $\begin{array}{l}\text { Basic exclusions } \\
\quad \text { Missing covariates, instrumental variable, outcomes at age 23 }\end{array}$ & 9933 & 3448 \\
$\begin{array}{l}\text { Further Exclusions } \\
\quad \text { No overlap on predicted propensity score }\end{array}$ & 20 & 3428 \\
\hline
\end{tabular}


Table 2: Included and excluded observations: mean differences in select covariates

\begin{tabular}{|c|c|c|c|}
\hline Covariates & $\begin{array}{c}\text { Excluded } \\
\mathrm{N}=9,933\end{array}$ & $\begin{array}{l}\text { Included } \\
\mathrm{N}=3,448\end{array}$ & $\mathrm{p}$-value \\
\hline Cognitive ability, age 7 & $-0.05(1.23)$ & $0.12(1.12)$ & $<0.001$ \\
\hline Non-cognitive ability, age 11 & $8.9(9.14)$ & $7.2(8.08)$ & $<0.001$ \\
\hline Parents say pupil unhappy at primary school, age 7 & $6 \%$ & $6 \%$ & 0.40 \\
\hline Parents want pupil to stay in school & $73 \%$ & $77 \%$ & $<0.001$ \\
\hline Male & $52 \%$ & $49 \%$ & $<0.001$ \\
\hline \multicolumn{4}{|l|}{ No. of acute illnesses child suffered up until age 7} \\
\hline 0 & $19 \%$ & $18 \%$ & \\
\hline 1 & $30 \%$ & $28 \%$ & \\
\hline$>1$ & $51 \%$ & $53 \%$ & 0.12 \\
\hline \multicolumn{4}{|l|}{ No. of times child was hospitalized up until age 7} \\
\hline 0 & $72 \%$ & $70 \%$ & \\
\hline 1 & $22 \%$ & $24 \%$ & \\
\hline$>1$ & $6 \%$ & $6 \%$ & 0.09 \\
\hline \multicolumn{4}{|l|}{ Height at age 7 (in $\mathrm{cm})$} \\
\hline Epilepsy in family, until age 7 & $6.9 \%$ & $7.3 \%$ & 0.37 \\
\hline Presence of chronic illnesses in the family & $2.2 \%$ & $2.5 \%$ & 0.25 \\
\hline \multicolumn{4}{|l|}{ Father SES } \\
\hline Low & $24 \%$ & $19 \%$ & \\
\hline Middle & $52 \%$ & $53 \%$ & \\
\hline High & $26 \%$ & $28 \%$ & 0.001 \\
\hline Financial hardship episode (un till child age 7) & $8.2 \%$ & $6.6 \%$ & 0.008 \\
\hline$\%$ of population unemployed or disabled & $5.1 \%$ & $4.5 \%$ & $<0.001$ \\
\hline$\%$ of women in formal employment & $41.3 \%$ & $41.1 \%$ & 0.80 \\
\hline $\begin{array}{l}\% \text { of population in employed in mining and } \\
\text { manufacturing }\end{array}$ & $37.2 \%$ & $37.4 \%$ & 0.66 \\
\hline$\%$ of population in employed in agriculture & $2.4 \%$ & $2.7 \%$ & 0.26 \\
\hline$\%$ of population in professional / managerial jobs & $11.8 \%$ & $12.5 \%$ & 0.02 \\
\hline$\%$ of population in unskilled workers & $7.6 \%$ & $6.8 \%$ & $<0.001$ \\
\hline$\%$ of population who is home owner & $42.7 \%$ & $48.5 \%$ & $<0.001$ \\
\hline$\%$ of population who is immigrant & $1.6 \%$ & $1.4 \%$ & 0.05 \\
\hline
\end{tabular}


Table 3: Treatment and control group observations: mean differences in select covariates

\begin{tabular}{|c|c|c|c|c|}
\hline Covariates & $\begin{array}{c}\text { Selective } \\
\mathrm{N}=1,602 \\
(47 \%)\end{array}$ & $\begin{array}{c}\text { Comprehensive } \\
\mathrm{N}=1,826 \\
(53 \%)\end{array}$ & p-value & $\begin{array}{l}\text { p-value } \\
\text { (across } \\
\text { IV } \\
\text { median) }\end{array}$ \\
\hline Cognitive ability, age 7 & $0.25(1.1)$ & $0.05(1.1)$ & $<0.001$ & 0.32 \\
\hline Non-cognitive ability, age 11 & $6.95(7.7)$ & $7.74(8.7)$ & 0.21 & 0.06 \\
\hline $\begin{array}{l}\text { Parents say pupil unhappy at primary school, } \\
\text { age } 7\end{array}$ & $5.6 \%$ & $6.9 \%$ & 0.50 & 0.08 \\
\hline Parents want pupil to stay in school & $78 \%$ & $77 \%$ & 0.51 & 0.60 \\
\hline Male & $48 \%$ & $49 \%$ & 0.30 & 0.83 \\
\hline $\begin{array}{l}\text { No. of acute illnesses child suffered up until age } \\
7\end{array}$ & & & & \\
\hline 0 & $17 \%$ & $20 \%$ & & \\
\hline 1 & $30 \%$ & $27 \%$ & & \\
\hline$>1$ & $53 \%$ & $53 \%$ & 0.13 & 0.55 \\
\hline $\begin{array}{l}\text { No. of times child was hospitalized up until age } \\
7\end{array}$ & & & & \\
\hline 0 & $69 \%$ & $71 \%$ & & \\
\hline 1 & $25 \%$ & $23 \%$ & & \\
\hline$>1$ & $6 \%$ & $6 \%$ & 0.31 & 0.10 \\
\hline Height at age 7 (in $\mathrm{cm})$ & $122.7(5.6)$ & $123.0(5.7)$ & 0.48 & 0.37 \\
\hline Epilepsy in family, until age 7 & $7.4 \%$ & $7.5 \%$ & 0.91 & 0.22 \\
\hline Presence of chronic illnesses in the family & $2.3 \%$ & $2.6 \%$ & 0.50 & 0.67 \\
\hline Father SES & & & & \\
\hline Low & $18 \%$ & $19 \%$ & & \\
\hline Middle & $53 \%$ & $54 \%$ & & \\
\hline High & $29 \%$ & $26 \%$ & 0.23 & 0.11 \\
\hline Financial hardship episode (until child age 7) & $5.1 \%$ & $6.6 \%$ & 0.24 & 0.36 \\
\hline$\%$ of population unemployed or disabled & $4.3 \%$ & $4.3 \%$ & 0.67 & 0.74 \\
\hline$\%$ of women in formal employment & $40.3 \%$ & $42.2 \%$ & 0.30 & 0.20 \\
\hline $\begin{array}{l}\% \text { of population in employed in mining and } \\
\text { manufacturing }\end{array}$ & $35.7 \%$ & $37.6 \%$ & 0.001 & 0.03 \\
\hline$\%$ of population in employed in agriculture & $2.9 \%$ & $2.6 \%$ & 0.30 & 0.65 \\
\hline $\begin{array}{l}\text { \% of population in professional / managerial } \\
\text { jobs }\end{array}$ & $13.0 \%$ & $12.3 \%$ & 0.01 & 0.54 \\
\hline$\%$ of population in unskilled workers & $6.5 \%$ & $6.7 \%$ & 0.04 & 0.48 \\
\hline$\%$ of population who is home owner & $50.0 \%$ & $47.1 \%$ & $<0.001$ & 0.19 \\
\hline$\%$ of population who is immigrant & $1.8 \%$ & $1.6 \%$ & 0.29 & 0.93 \\
\hline
\end{tabular}


Table 4: Effect of comprehensive schooling on depression at ages 23, 33 and 42

\begin{tabular}{lccc}
\hline & \multicolumn{3}{c}{ Effect on Pr(Depression) } \\
\cline { 2 - 4 } & $\begin{array}{c}\text { at Age 23 } \\
\text { Mean (s.e.) }\end{array}$ & $\begin{array}{c}\text { at Age 33 } \\
\text { Mean (s.e.) }\end{array}$ & $\begin{array}{c}\text { at Age 42 } \\
\text { Mean (s.e.) }\end{array}$ \\
\hline $\mathrm{N}$ & 3426 & 2831 & 2775 \\
Unadjusted & $.001(.009)$ & $0.014(0.009)$ & $0.015(0.012)$ \\
PeT-based & & & \\
$\quad$ ATE & $0.02(0.08)$ & $0.09(0.11)$ & $0.14(0.11)$ \\
TT & $-0.005(0.08)$ & $0.07(0.17)$ & $0.11(0.08)$ \\
$\quad$ TUT & $0.05(0.09)$ & $0.12(0.17)$ & $0.17(0.15)$ \\
\hline
\end{tabular}


Table 5: Variance decomposition: factors explaining variation in individual effects on depression at Age 42

\begin{tabular}{l|c}
\hline Factors & $\begin{array}{c}\text { \% of total variance in PeT } \\
\text { effects on Depression at Age } \\
\text { 42 explained }\end{array}$ \\
\hline Parent say pupil unhappy at primary school, age 7 & 22 \\
Non-cognitive ability, age 11 & 16 \\
Height, age 7 & 14 \\
Cognitive ability, age 7 & 12 \\
No. of hospitalizations, by age 7 & 9 \\
Parents want pupil to stay in school & 6 \\
Male & 5 \\
\hline
\end{tabular}

NOTE: Only factors explaining at least 5\% of total variance are reported 
Table 6: Primary identifiers for individuals for whom comprehensive school would have significant increase in probability of depression by age 42. (Stepwise backward logistic with very stringent inclusion criteria. i.e. LR p-value < 0.0001)

\begin{tabular}{l|c}
\hline Covariates & Odds Ratio \\
\hline Non-cognitive ability, age 11 & $1.1(0.01)$ \\
Parents say pupil unhappy at primary school, age 7 & $0.02(0.01)$ \\
Parents want pupil to stay in school & $36.8(12.6)$ \\
Male & $28.6(6.8)$ \\
No. of times child was hospitalized up until age $7: 1$ (ref 0$)$ & $0.03(0.01)$ \\
No. of times child was hospitalized up until age $7:>1$ & $4.5(1.2)$ \\
Father SES - middle & $0.03(0.06)$ \\
$\%$ of population in employed in mining and manufacturing & $10.1(4.6)$ \\
\hline
\end{tabular}


Table 7: PeT effect of comprehensive schooling on the probability of cohort-member being cigarette smokers at ages 23, 33 and 42

\begin{tabular}{|l|c|c|c|}
\hline & $\begin{array}{c}\text { Smoking at Age 23 } \\
\text { Mean (s.e.) }\end{array}$ & $\begin{array}{c}\text { Smoking at Age 33 } \\
\text { Mean (s.e.) }\end{array}$ & $\begin{array}{c}\text { Smoking at Age 42 } \\
\text { Mean (s.e.) }\end{array}$ \\
\hline $\mathrm{N}$ & 3426 & 2831 & 2775 \\
\hline Unadjusted & $.034(.02)$ & $.03(.017)$ & $.017(.016)$ \\
\hline PeT-based & & & $0.05(0.10)$ \\
\hline ATE & $0.10(0.14)$ & $0.15(0.12)$ & $0.04(0.10)$ \\
\hline TT & $0.11(0.14)$ & $0.13(0.11)$ & $0.05(0.10)$ \\
\hline TUT & $0.10(0.13)$ & $0.17(0.13)$ & \\
\hline
\end{tabular}




\section{APPENDIX}

\section{Intuitive explanation on the identification of Person-centered Treatment (PeT) effects using local instrumental variable methods.}

Suppose that in our example, we presume (only to get the general intuition)

comprehensive schooling to be more beneficial, in terms of long-term health, for children with higher test scores in elementary schools and for children who are selfconfident. Moreover, choice of treatment is influenced by test scores and the selfconfidence of the child. However, our data on children from NCDS do not have a measure of their self-confidence, and only contains for each student: test scores, treatment, long-term health outcomes, and a characteristic that all agree is a powerful and valid instrument. Let the instrument be a continuous variable (e.g. distance to the comprehensive school). Greater the distance to the comprehensive, less likely will be the enrolment to that school.

In this case, a traditional naïve regression would produce biased estimate of the average treatment effect (ATE) and also the conditional average treatment effects (CATEs) for children groups with low and high test scores groups due to the endogeneity of the treatment status caused by the missingness of self-confidence levels in the analysis.

A traditional instrumental variable analysis, using a strong and valid IV, will also produce biased estimates for ATE and CATEs due to the presence of essential heterogeneity, which suggests that the treatment effects vary over unobserved confounders, which in this case is the self-confidence status. 
A local instrumental variable (LIV) approach can be used to overcome these issues when a continuous instrument is available. LIV methods are used to estimate the marginal treatment effects (MTEs) parameters. MTEs are the effects for individuals for whom the influence of the observed characteristics (tests score and distance to comprehensive school) balance with the influence of the unobserved confounders (self-confidence level) on treatment choice such that they are indifferent to choosing between using the comprehensive and selective schools. To estimate an MTE, LIV methods compare the outcomes of two groups of, say, students with low test scores, where one group is staying at a distance $d$ from the comprehensive school and the other at a distance $d+\varepsilon, \varepsilon$ representing an epsilon (very small) change in distance. Therefore, the two groups are identical in their distribution of self-confidence. Any difference in outcomes between these two groups of students should be attributed to the changes in treatment choices between these two groups, which is only brought about by the difference in distance. However, since the difference in distance is very small, the effect can be attributed to a margin of students who were indifferent between two treatment options and were moved to change treatment choice by the small perturbation of the instrumental variable, i.e., distance. For this margin of stduents, one can quantify a normalized level of unobserved confounders as they must balance the observed levels. Similarly, for another dyad of distances, $d^{\prime}$ and $d^{\prime}+\varepsilon$, one can estimate another MTE, which reflects the causal treatment effect on students at another level of unobserved confounder. In this way, a full schedule of MTEs can be estimated that vary over the unobserved confounder levels (i.e. self-confidence) given any level of the observed confounder (i.e. test scores). Intuitively, LIV methods estimates these MTEs by estimating the partial derivate of the outcome with respect to the IV-based propensity score (reflecting epsilon changes). 
Once MTEs are estimated over the range of observed and unobserved levels, they can then be easily aggregated to form meaningful treatment effect parameters such as the ATE, CATEs, TT and TUT and also study heterogeneity in effects using personcentered treatment (PeT) effects. The Pe'T effect for a student in this stylized sample is conditioned not only on that individual's test score but his test score-specific MTEs are also averaged over a distribution of self-confidence statuses that conforms with the individual's observed choice of schooling system. Thus these are deemed to be personalized effect for this student. 


\section{APPENDIX}

Table A.1

Pre-schooling and secondary school characteristics

\begin{tabular}{|c|c|}
\hline & Variables \\
\hline $\begin{array}{l}\text { Pre-schooling } \\
\text { characteristics }\end{array}$ & $\begin{array}{l}\text { Cognitive ability score (age 7) } \\
\text { Relative rank of cognitive ability (age 11) } \\
\text { Non-cognitive ability (BSAG) score (age 11) } \\
\text { Number of children in primary school class (age 7) } \\
\text { Indicator for unhappy at primary school (age 7) } \\
\text { Indicator for parents' wanting child to stay in school } \\
\text { Indicator for male } \\
\text { Morbidity index (age 7) } \\
\text { Number of hospitalisations (age 7) } \\
\text { Indicator for diabetes in family } \\
\text { Indicator for epilepsy in family } \\
\text { Indicator for heart disease in family } \\
\text { Indicator for father chronically ill } \\
\text { Indicator for mother chronically ill } \\
\text { Indicator for father's occupational SES professional } \\
\text { Indicator for father's occupational SES other non-manual } \\
\text { Indicator for single parent family } \\
\text { Indicator for financial hardship in family (age 7) } \\
\text { Enumeration district: percentage unemployed/long-term sick } \\
\text { Enumeration district: percentage women working } \\
\text { Enumeration district: percentage employed in manufacturing } \\
\text { Enumeration district: percentage emplyed in agriculture } \\
\text { Enumeration district: percentage in professional/managerial } \\
\text { occupations } \\
\text { Enumeration district: percentage in other non-manual occupations } \\
\text { Enumeration district: percentage in skilled manual occupations } \\
\text { Enumeration district: percentage in semi-skilled manual occupations } \\
\text { Enumeration district: percentage in unskilled manual occupations } \\
\text { Enumeration district: percentage owner occupiers } \\
\text { Enumeration district: percentage council tenants } \\
\text { Enumeration district: percentage non-white } \\
\text { Enumeration district: percentage immigrants } \\
\text { Indicator for change of residence between LEAs (age 7) } \\
\text { Indicators for Standard Regions }\end{array}$ \\
\hline $\begin{array}{l}\text { Secondary } \\
\text { school } \\
\text { characteristics }\end{array}$ & $\begin{array}{l}\text { Indicator for single sex school } \\
\text { Indicator for streaming by ability within school } \\
\text { Pupil-teacher ratio } \\
\text { Ratio of expelled to total pupils }\end{array}$ \\
\hline
\end{tabular}


Table A.2

Detailed measure of educational attainment

\begin{tabular}{lc}
\hline \hline & $\%$ \\
\hline No grade at CSE, GCE O or A levels & 20.6 \\
1+ passes at O level, grades 4 or 5 only & 0.6 \\
1+ passes at CSE, grades 4 or 5 only & 8.2 \\
1+ passes at CSE, grades 2 or 3 & 9.5 \\
5+ passes at CSE, grades 2 to 5 & 13.6 \\
1-4 passes at GCE O level or CSE grade 1 & 25.5 \\
5 or 6 passesGCE O level or CSE 1 & 5.0 \\
7+ passes at GCE O level grades A-C, or CSE grade 1 & 3.5 \\
1 pass at A level, grades A-E & 2.9 \\
2 passes at A levels, up to 8pts & 3.7 \\
3+ passes at A levels, up to 8pts & 2.7 \\
2 passes at A levels and 9+ pts & 0.2 \\
3+ passes at A levels and 9+pts & 4.0 \\
\hline
\end{tabular}

Note: A level points are allocated as 5, 4, 3, 2 and 1 for grades A-E respectively.

Table A.3

Breakdown of long-standing illness (LSI) by percentage with specific main conditions (ICD-10)

\begin{tabular}{lc}
\hline \hline & $\begin{array}{c}\text { Wave } 7 \\
\text { (age 46) }\end{array}$ \\
\hline Infectious \& parasitic diseases & 0.7 \\
Neoplasms & 1.6 \\
Diseases of blood \& immune mechanism & 1.5 \\
Endocrine, nutritional and metabolic & 9.5 \\
Mental and behavioral disorders & 5.9 \\
Nervous system & 5.9 \\
Eye, ear and mastoid process & 4.6 \\
Circulatory system & 11.8 \\
Respiratory system & 11.4 \\
Digestive system & 5.5 \\
Skin & 2.1 \\
Muscoloskeletal system & 25.7 \\
Genitourinary system & 2.0 \\
Congenital malformations & 0.3 \\
Undiagnosed illness & 1.8 \\
Injury, poisoning etc & 5.3 \\
Other LSI/uncoded & 4.3 \\
\hline
\end{tabular}


Table A.4

First-stage regression results.

\begin{tabular}{|c|c|c|c|c|}
\hline Covariates & Coefficient & p-value & \multicolumn{2}{|c|}{ [95\% confidence Interval] } \\
\hline Cognitive ability, age 7 & $-0.09(0.03)$ & 0.002 & -0.15 & -0.03 \\
\hline Non-cognitive ability, age 11 & $0.001(0.002)$ & 0.6 & -0.003 & 0.01 \\
\hline Parents say pupil unhappy at primary school, age 7 & $0.02(0.08)$ & 0.835 & -0.15 & 0.18 \\
\hline Parents want pupil to stay in school & $0.11(0.06)$ & 0.055 & 0.005 & 0.23 \\
\hline Male & $0.03(0.04)$ & 0.481 & -0.05 & 0.11 \\
\hline No. of acute illnesses child suffered up until age $7: 1$ (ref 0 ) & $-0.1(0.06)$ & 0.111 & -0.22 & 0.02 \\
\hline No. of acute illnesses child suffered up until age $7:>1$ & $-0.03(0.07)$ & 0.662 & -0.16 & 0.1 \\
\hline No. of times child was hospitalized up until age $7: 1$ (ref 0$)$ & $-0.09(0.05)$ & 0.05 & -0.19 & 0.0005 \\
\hline No. of times child was hospitalized up until age $7:>1$ & $-0.22(0.1)$ & 0.033 & -0.42 & -0.02 \\
\hline Height at age 7 (in $\mathrm{cm})$ & $0.002(0.004)$ & 0.672 & -0.01 & 0.01 \\
\hline Epilepsy in family, until age 7 & $-0.07(0.08)$ & 0.39 & -0.23 & 0.09 \\
\hline Presence of chronic illnesses in the family & $0.05(0.14)$ & 0.694 & -0.22 & 0.33 \\
\hline Father SES - high ( Ref: 'low SES') & $-0.07(0.08)$ & 0.344 & -0.23 & 0.08 \\
\hline Father SES - middle (Ref: 'low SES') & $0.03(0.06)$ & 0.667 & -0.09 & 0.14 \\
\hline Financial hardship episode (un till child age 7 ) & $-0.02(0.08)$ & 0.766 & -0.19 & 0.14 \\
\hline Northwest & $-0.13(0.19)$ & 0.483 & -0.5 & 0.23 \\
\hline EW riding & $0.53(0.23)$ & 0.02 & 0.08 & 0.99 \\
\hline North Midlands & $-0.07(0.21)$ & 0.75 & -0.47 & 0.34 \\
\hline Midlands & $0.13(0.17)$ & 0.453 & -0.21 & 0.47 \\
\hline East & $0.08(0.23)$ & 0.706 & -0.36 & 0.53 \\
\hline Southeast & $-0.08(0.2)$ & 0.697 & -0.48 & 0.32 \\
\hline Southwest & $0.04(0.21)$ & 0.843 & -0.37 & 0.45 \\
\hline Wales & $0.55(0.24)$ & 0.02 & 0.09 & 1.02 \\
\hline$\%$ of population unemployed or disabled & $-0.12(0.38)$ & 0.755 & -0.85 & 0.62 \\
\hline$\%$ of women in formal employment & $0.2(0.12)$ & 0.109 & -0.04 & 0.43 \\
\hline$\%$ of population in employed in mining and manufacturing & $0.15(0.2)$ & 0.443 & -0.24 & 0.55 \\
\hline$\%$ of population in employed in agriculture & $-0.21(0.24)$ & 0.386 & -0.68 & 0.26 \\
\hline$\%$ of population in professional / managerial jobs & $0.16(0.23)$ & 0.484 & -0.3 & 0.62 \\
\hline$\%$ of population in unskilled workers & $0.01(0.32)$ & 0.974 & -0.62 & 0.64 \\
\hline$\%$ of population who is home owner & $-0.33(0.09)$ & 0.000 & -0.5 & -0.16 \\
\hline$\%$ of population who is immigrant & $-0.29(0.43)$ & 0.5 & -1.13 & 0.55 \\
\hline IV: \% comprehensive schools (F-stat for IV is 83 ) & $0.02(0.004)$ & 0.000 & 0.008 & 0.03 \\
\hline Constant & $-0.44(0.54)$ & 0.421 & -1.51 & 0.63 \\
\hline
\end{tabular}


